\section{Knowledge and Attitudes of AIDS Health Care Providers Before and After Education Programs}

\author{
DOROTHY C. WERTZ, PhD \\ JAMES R. SORENSON, PhD \\ LINETTE LIEBLING, MSPH \\ LAWRENCE KESSLER, BA \\ TIMOTHY C. HEEREN, PhD
}

\begin{abstract}
This study was supported by a grant from the Massachusetts Department of Public Health. Dr. Wertz is Associate Research Professor, Health Services Section, Boston University School of Public Health. Dr. Sorenson is Professor and Chair, Health Education Department, School of Public Health, University of North Carolina at Chapel Hill. Ms. Liebling is City AIDS Coordinator, Department of Health and Hospitals, Boston; she was Educational Director for the AIDS Action Committee of Massachusetts. Mr. Kessler is Director of the AIDS Action Committee of Massachusetts. Dr. Heeren is Assistant Professor of Epidemiology and Biostatistics, Boston University School of Public Health.

Tearsheet requests to Dorothy C. Wertz, PhD, School of Public Health, Boston University, 80 East Concord St., Boston, MA 02118.
\end{abstract}

Synopsis...........................

Analysis of the responses of 1,247 health care providers to questionnaires immediately before and after educational programs on acquired immuno- deficiency syndrome (AIDS) revealed significant $(P<.05)$ improvements in accuracy of knowledge about 7 of 15 modes of transmission and 7 of 11 means of infection control. Sizeable percentages, however, continued to believe after the programs that AIDS could be transmitted by casual contact, such as sharing coffee cups.

Provider attitudes about caring for persons with AIDS shifted in the direction desired $(P<.001)$ on six of nine questions. After programs, 92 percent believed that they had sufficient knowledge to protect themselves from getting AIDS, and 79 percent felt professionally competent to care for a person with AIDS. Both before and after programs, providers who established regulations for the care of persons with AIDS and outpatient care providers had the most accurate knowledge and felt most comfortable with persons with AIDS, while inpatient care providers had the least accu. rate knowledge and felt least comfortable.

A 1-month followup of 159 providers revealed that postprogram changes in knowledge and attitudes were largely retained. Results point to the need for education at all levels of the health care system, to a persistent gap in knowledge and attitudes between those persons who establish regulations and those who carry them out, and to the possibility of creating significant changes through education.
As THE NUMBER OF PERSONS WITH acquired
immunodeficiency syndrome (AIDS) increases,
most of the nation's health care workers will need
to learn how to care for people with AIDS and
how to avoid exposure to the AIDS virus, which is
named the human immunodeficiency virus (HIV)
$(1,2)$. The evidence suggests that many providers
are uneasy about the idea of caring for someone
with AIDS $(3,4)$. Many providers do not know
how AIDS is transmitted. All too frequently,
health care providers use infection control precau-
tions that are appropriate only for airborne infec-
tions, such as quarantine of the room or wearing
of masks or gowns, while at the same time they risk exposure to the AIDS virus by recapping needles (5-13).

\section{Programs and Goals}

To meet the need for education of health care providers, the AIDS Action Committee of Massa ${ }^{1}$ chusetts, under a research grant from the Massachusetts Department of Public Health, initiated a series of onsite educational programs in February 1985. The programs' goals were $(a)$ to teach providers how to protect themselves from getting AIDS in the course of their professional duties, (b) to enable providers to feel comfortable caring for 
persons with AIDS, and (c) to ensure that persons with AIDS are treated with dignity and with the highest level of professional care. Typically, programs began with a lecture-information format and moved to a question-and-answer period. All programs were conducted by an MSPH health educator with special training by Boston area physicians who are experts on AIDS. The health educator kept abreast of current developments by attending local, national, and international scientific conferences, including the first international conference on AIDS, held in Atlanta, GA.

The typical 90-minute program for health care providers included discussion of $(a)$ epidemiology of AIDS, (b) modes of transmission, (c) means of preventing transmission, (d) general infection control producedures, and $(e)$ psychosocial issues for persons with AIDS and those who care for them. When time permitted, the presenter also discussed the costs of care, hospices, and other out-ofhospital alternatives, and legal and political issues. The health educator made the bulk of the presentations. In addition, at one-third of the programs a physician experienced in the treatment of AIDS gave a specialized talk on current research. At another third of the progams, a man with AIDS described his experience with the disease and with hospitals. He invited members of the audience to view and touch his Kaposi's sarcoma lesions, which are not infectious. Program organizers anticipated that these techniques would help overcome some providers' fear and avoidance of persons with AIDS. All programs stressed the fact that people with AIDS can continue to have their usual, nonsexual, social contacts throughout the course of the disease without infecting others.

\section{Methods}

During the 4 months between February 11 and June 15, 1985, the AIDS Action Committee offered educational programs at 36 sites in Massachusetts, including public, private, and veterans' hospitals; acute and chronic care facilities; alcohol rehabilitation units; hospices; community health centers; and main offices of visiting nurse associations. The health educator of the AIDS Action Committee contacted infection control personnel or administrators at the sites through a letter describing the programs, which were available at no cost to institutions or participants.

The primary objective of the AIDS Action Committee and participating institutions was educational intervention in the AIDS crisis, rather
'As the number of persons with AIDS

increases, most of the nation's health

care workers will need to learn how to

care for people with AIDS and how to

avoid exposure to the AIDS

virus....

than formal research. Hospitals and visiting nurse associations usually made attendance mandatory for all nursing, housekeeping, and support staff. To make sure that programs reached the entire staff, supervisors took formal attendance. Programs given during the day were taped and shown to the night staff and vice versa. Given the pressure for immediate education to meet hospitals' projected needs for patient care, it was not possible to select a random sample of providers or a control group.

The AIDS Action Committee regarded these educational programs as pioneering efforts to obtain a professional standard of care, while at the same time teaching health care workers how to avoid exposure. To improve the effectiveness of future programs, the AIDS Action Committee requested an evaluation of stability and change in providers' knowledge and attitudes from before to immediately after the programs, with a subset of at least 200 providers to be followed up at 1 month.

Questionnaires were distributed to all participants at the outset of each program. Subjects were asked to complete the first part (55 items) before the program and the second part (43 items) immediately afterwards. Each part was designed to take no more than 5 minutes to complete. In addition to sociodemographic and job experience data, which were collected only on the preprogram questionnaires, both forms gathered information about participants' knowledge of 15 modes of transmission, 11 means of preventing transmission (infection control), and 9 professional and personal attitudes about persons with AIDS and their care. Additional questions were asked about providers' fears of getting AIDS or ARC (AIDSrelated complex), whether they believed hepatitis B precautions are effective in preventing transmission of AIDS, how they planned to treat persons with AIDS, and whether they thought their coworkers or supervisors agreed with their treatment plans. 
Table 1. Demographic characteristics of 1,247 AIDS health care providers in study sample who attended an educational program

\begin{tabular}{|c|c|}
\hline Characteristic & Percent \\
\hline \multicolumn{2}{|l|}{ Job title: } \\
\hline$\ldots \ldots \ldots$ & 49 \\
\hline Licensed practical nurse $\ldots \ldots \ldots \ldots \ldots$ & 13 \\
\hline 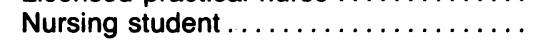 & 5 \\
\hline Support staff. . . . . . . . . . . . . . & 12 \\
\hline Laboratory technician. . . . . . . . . . . . . . & 6 \\
\hline Physician or medical student . . . . . . . . . & 2 \\
\hline Other $\ldots \ldots \ldots \ldots \ldots \ldots \ldots \ldots \ldots \ldots$ & $1 \overline{3}$ \\
\hline Mean years of education . . . . . . . . . . . & 15 \\
\hline Age, years $($ mode $) \ldots \ldots \ldots \ldots \ldots \ldots \ldots$ & $35-39$ \\
\hline Sex (female) $\ldots \ldots \ldots \ldots \ldots \ldots \ldots \ldots \ldots$ & 89 \\
\hline \multicolumn{2}{|l|}{ Religion: } \\
\hline Catholic ........ & 63 \\
\hline Protestant $\ldots \ldots \ldots \ldots \ldots \ldots \ldots \ldots \ldots$ & 26 \\
\hline Jewish $\ldots \ldots \ldots \ldots \ldots \ldots \ldots \ldots \ldots \ldots$ & 4 \\
\hline 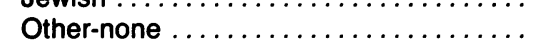 & 7 \\
\hline Race (white) $\ldots \ldots \ldots \ldots \ldots \ldots \ldots$ & 97 \\
\hline Cared for person with AIDS . . . . . . . . & 20 \\
\hline
\end{tabular}

1 Includes persons listed as registered nurses, Bachelor of Science in Nursing, Master of Science in Nursing, or nurse supervisor.

Approximately 90 percent of those who attended programs filled out the two questionnaires. A total of 1,247 providers participated in the study.

To assess whether the presentations had more than a temporary effect, we planned a followup at 1 month on a volunteer subsample. All persons who attended programs during a 2 -month period were asked, through a brief letter attached to their questionnaries, to provide their names and addresses if they wished to participate in a mail followup. Of approximately 600 persons whose participation was solicited, 210 volunteered, with the understanding that their questionnaires would be identified by numbers only. Of the 210 volunteers, 159 (76 percent) returned the mailed questionnaires. Followup questionnaires were the same as those used immediately after the program. On account of the small size and self-selection of the followup group, we have concentrated on the results immediately after the program.

\section{Results}

Table 1 presents selected sociodemographic data. Nearly a majority of providers were nurses. Most providers were female, between 35 and 39 years of age. A majority were Catholic, white, and had a mean of 15 years of formal education; 20 percent had cared for a person with AIDS.

Providers' knowledge about 15 different modes of transmission of AIDS to health care workers is summarized in table 2. To date there has been only one case in which a preexposure serum sample was available to document seroconversion after a needlestick, and a complete epidemiologic evaluation of that health care provider was made (15). Although two other cases of HIV-positive antibody tests after needlesticks have been reported, preexposure serum samples were not available (16). Although transmission has not occurred through working with specimens of blood or urine or assisting at autopsy, infection control procedures of the Centers for Disease Control (CDC) (14) advise special precautions for persons who perform these tasks. None of the other 12 modes listed poses a threat to health care workers.

Most providers were already aware, before the programs, of the possibility of transmission through needlesticks or working with specimens of blood, and from 88 to 91 percent were aware of the possibility of transmission at autopsy. Providers' beliefs about the other 12 modes of transmission, however, reveal a need for education.

In describing modes of transmission, the programs emphasized that AIDS is transmitted only by specific modes outside the realm of ordinary social contact or patient care. After the programs, there were significant improvements in accuracy of knowledge about many, but not all, modes of transmission. In one instance knowledge was significantly less accurate after the programs than it had been before. We have no immediate explanation for this finding. These were pilot programs, conducted without time for extensive needs assessment, and educators were perhaps unaware which topics most needed emphasis.

Knowledge about 11 means of preventing transmission is reported in table 3 . Before the programs, 53 percent of the providers were unaware of CDC recommendations that they not recap needles used on persons with AIDS because recapping exposes them to the risk of a needlestick (14). After the programs, 96 percent of providers were aware that needles used on persons with AIDS should be discarded immediately without recapping.

The shift toward accuracy of knowledge was significant $(P<.001)$ with regard to five means of infection control and significant $(P<.05)$ with regard to two means. The programs emphasized the efficacy of hepatitis B precautions in preventing the transmission of AIDS to health care workers. After the programs, 94 percent of providers agreed that hepatitis B precautions were effective or very effective. 
AIDS Action Committee programs were directed toward changing attitudes as well as increasing knowledge. Table 4 lists nine professional and personal attitudes before and after the programs. Before the programs, almost all providers (96 percent) said that it was very unlikely that they would get AIDS by any means whatsoever, including means outside the course of professional duties. Similar percentages (not reported in table 4) said that it was very unlikely that they would get ARC (AIDS-related complex) and that they "never" thought of the possibility of getting AIDS or ARC.

After the programs, provider attitudes shifted at the $P<.001$ level on six of the nine questions. With the exception of outpatient care providers, significantly more providers $(a)$ believed that they had sufficient knowledge to protect themselves from getting AIDS, (b) felt professionally competent to care for a person with AIDS, and (c) would feel comfortable interacting with the person's lover. Significantly fewer said that if they had a choice they would avoid caring for persons (with AIDS or that if they got AIDS other people swould think that they were homosexuals. Significantly more thought that persons with AIDS could have nonsexual social contacts. There were no significant changes in response to three questions: agreement that hospital workers should not be required to work with AIDS patients, agreement that they were not morally offended by people with AIDS, and belief that it is very unlikely that they would get AIDS. Programs that included a person with AIDS or a physician on the panel did not differ significantly from other programs in changing knowledge or attitudes.

Knowledge and levels of responsibility. As a subanalysis, we categorized providers into four groups on the basis of their level of responsibility in the health care hierarchy. These groups are persons who establish regulations for the care of persons with AIDS, supervisors, inpatient care providers, and outpatient care providers. The rationale for dividing providers into four groups is twofold. First, we hypothesized that providers at different levels of responsibility might come to the programs with different levels of experience and knowledge, and therefore might have different educational needs. Second, knowledge or attitudinal differences among these groups could affect the functioning of organizations and the care of persons with AIDS.

On the preprogram questionnaires, participants
Table 2. Percentage of 1,247 providers believing AIDS virus can be transmitted by different modes, before and after educational programs

\begin{tabular}{|c|c|c|}
\hline Modes of transmission & Before & After \\
\hline \multicolumn{3}{|l|}{ Discussed at all programs: } \\
\hline $\begin{array}{l}\text { Needlestick with a needle used on } \\
\text { a person with AIDS............... } \\
\text { Mouth-to-mouth cardiopulmonary }\end{array}$ & 99 & 98 \\
\hline resuscitation $\ldots \ldots \ldots \ldots \ldots \ldots \ldots$ & 90 & 88 \\
\hline coffee cups $\ldots \ldots \ldots \ldots \ldots \ldots \ldots$ & 74 & 72 \\
\hline Shaking hands $\ldots \ldots \ldots \ldots \ldots \ldots \ldots$ & 30 & 111 \\
\hline Doorknobs................. & 24 & 29 \\
\hline Touching equipment. . . . . . . . . . & 49 & 230 \\
\hline Being in the same room ......... & 17 & 14 \\
\hline \multicolumn{3}{|l|}{$\begin{array}{l}\text { Discussed at all educational } \\
\text { programs for outpatient care } \\
\text { workers: }\end{array}$} \\
\hline Working with specimens of blood or & & \\
\hline Cleaning vomitus. . . . . . . . . . . . & $\begin{array}{l}98 \\
79\end{array}$ & $\begin{array}{r}99 \\
387\end{array}$ \\
\hline Toilet seats $\ldots \ldots \ldots \ldots \ldots \ldots \ldots$ & 59 & 246 \\
\hline Bedsheets. . . . . . . . . . . & 54 & 146 \\
\hline Doing laundry.............. & 47 & ${ }^{1} 36$ \\
\hline \multicolumn{3}{|l|}{$\begin{array}{l}\text { Not generally discussed at } \\
\text { educational programs: }\end{array}$} \\
\hline Assisting at autopsy ..... & 91 & 88 \\
\hline Emptying bedpans ....... & 77 & ${ }^{1} 82$ \\
\hline Sneezing, coughing $\ldots \ldots \ldots \ldots \ldots$ & 55 & 51 \\
\hline
\end{tabular}

1 Significant change in desired direction at $P<.05$ (McNemar test).
${ }^{2}$ Significant change in desired direction at $P<.00$ (McNemar test).
${ }^{3}$ Significant change in direction not desired at $P<.05$ (McNemar test).

Table 3. Percentage of 1,247 providers believing practices are always necessary to prevent transmission of AIDS virus, before and after educational programs

\begin{tabular}{|c|c|c|}
\hline Means of preventing transmission of AIDS & Before & After \\
\hline \multicolumn{3}{|l|}{ Immediate discarding of needles, } \\
\hline $\begin{array}{l}\text { Blood precautions } \ldots \ldots \ldots \ldots \\
\text { Handwashing before and after }\end{array}$ & 98 & 99 \\
\hline contact $\ldots \ldots \ldots \ldots \ldots \ldots \ldots$ & 92 & 92 \\
\hline Special handling of body fluids . . . . . & 93 & 94 \\
\hline Gowns $\ldots \ldots \ldots \ldots \ldots \ldots \ldots$ & 26 & 15 \\
\hline Masks.................... & 25 & 17 \\
\hline Gloves .................. & 45 & 233 \\
\hline Shoe protectors . . . . . . . . . . & 6 & 21 \\
\hline Double gloves. . . . . . . . . . . . . . & 10 & 14 \\
\hline Protective eyewear & 7 & 2 \\
\hline Quarantine of patient's room ....... & 33 & 112 \\
\hline
\end{tabular}

1 Significant change in desired direction at $P<.00$ (McNemar test).
2 Significant change in desired direction at $P<.05$ (McNemar test).

were asked whether their responsibilities included establishing regulations for the care of persons with AIDS, supervision, inpatient care, outpatient care, and laboratory work. Most respondents listed two or more types of responsibilities. Few providers, for example, only established regulations without also supervising or participating in patient 
Table 4. Professional and personal attitudes of 1,247 providers about care of persons with AIDS, before and after educational programs

\begin{tabular}{|c|c|c|}
\hline Attitudes & Before & After \\
\hline $\begin{array}{l}\text { Have sufficient knowledge to protect } \\
\text { myself from getting AIDS.......... } \\
\text { Feel professionally competent to }\end{array}$ & 31 & 192 \\
\hline $\begin{array}{l}\text { care for a person with AIDS ........ } \\
\text { If I had a choice, I would prefer to } \\
\text { avoid caring for persons with }\end{array}$ & 34 & 179 \\
\hline AIDS $\ldots \ldots \ldots \ldots \ldots \ldots \ldots \ldots \ldots$ & 40 & 118 \\
\hline $\begin{array}{l}\text { I think hospital workers should not } \\
\text { be required to work with AIDS }\end{array}$ & & \\
\hline $\begin{array}{l}\text { patients } \ldots \ldots \ldots \ldots \ldots \ldots \ldots \ldots \\
\text { would feel comfortable interacting } \\
\text { withe lover of a person with }\end{array}$ & 16 & 16 \\
\hline $\begin{array}{l}\text { AIDS ........................... } \\
\text { If I got AIDS, other people would }\end{array}$ & 58 & 177 \\
\hline $\begin{array}{l}\text { think I'm a homosexual ............ } \\
\text { I am morally offended by people with }\end{array}$ & 36 & ${ }^{1} 27$ \\
\hline $\begin{array}{l}\text { AIDS .......................... } \\
\text { Persons with AIDS can have }\end{array}$ & 6 & 4 \\
\hline $\begin{array}{l}\text { nonsexual social contacts } \ldots \ldots \ldots \ldots \\
\text { It is very unlikely that I will get }\end{array}$ & 54 & 189 \\
\hline AIDS $\ldots \ldots \ldots \ldots \ldots \ldots$ & 96 & 97 \\
\hline
\end{tabular}

1 Significant shift at $P<.001$ (McNemar test).

care. We categorized as regulators all persons who said that their responsibilities included establishing regulations for the care of persons with AIDS, regardless of whether or not they also supervised or provided inpatient or outpatient care. We categorized as supervisors all providers who said that they had supervisory responsibilities but did not establish regulations. Persons who provided inpatient care but had no regulatory or supervisory responsibilities were categorized as inpatient care providers, regardless of whether or not they also provided some outpatient care. Persons who provided only outpatient care were categorized as outpatient care providers. In all, 149 persons fit the criteria for regulators, 345 for supervisors, 468 for inpatient care providers, and 85 for outpatient care providers, a total of 1,047 persons whose responsibilities directly affected patient care. An additional 200 respondents had no regulatory, supervisory, or patient care responsibilities. Most were students, clerical workers, technicians, or housekeeping staff.

The four groups differed at the $P<.001$ level on five of the seven characteristics listed in table 1: job title, education, age, sex, and percent who had cared for a person with AIDS. As expected, regulators were more likely than other groups to be nurses, have some education, and be older. Perhaps most important, 32 percent of the regulators had cared for a person with AIDS, as opposed to 18-21 percent in the other groups. Like regulators, supervisors had more education and were older than other groups; supervisors included a greater percentage of men than any other group. These characteristics help to determine one's place in the hierarchy; education and experience go hand in hand with being a regulator. Therefore, we would expect regulators to have more preprogram knowledge about AIDS than other groups.

We were interested in whether the groups differed in knowledge and attitude on the test taken before the program, and, if so, whether they still differed after the test. Before the programs, the four groups of providers differed at the $P<.05$ level with regard to the accuracy of their knowledge about 5 of the 15 modes of transmission: touching equipment, being in the same room, touching toilet seats and bedsheets, and doing laundry. After the programs, the groups differed significantly in their knowledge of 6 of the 15 modes: needlesticks, cardiopulmonary resuscitation (CPR), touching doorknobs, being in the same room, touching toilet seats, and sneezing or coughing. The groups also differed at the $P<.01$ level with regard to 5 of the 11 means of infection control: recapping needles and quarantine and wearing gowns, masks, and gloves. Both before and after the programs, regulators and outpatient care providers had the most accurate knowledge and inpatient care providers the least accurate knowledge.

Before the programs, the four groups of providers differed at the $P<.001$ level with regard to four of the nine attitudes: have sufficient knowledge to protect themselves from getting AIDS, feel professionally competent to care for persons with AIDS, feel comfortable interacting with the person's lover, and persons with AIDS can have nonsexual social contacts. Regulators felt the most confident and most comfortable with AIDS patients, while inpatient care providers felt the least confident and least comfortable. After the educational programs, there were still differences at the $P<.001$ level in the percentages who believed themselves competent to care for a person with AIDS and who said that they would feel comfortable with the person's lover. Again, regulators believed themselves most competent and comfortable, and inpatient care providers felt the least competent and comfortable.

One-month followup. Responses to the 1-month followup were compared with the same subjects' preprogram and postprogram responses, using the 
McNemar test, in order to see whether immediate changes after the program still remained significant. Changes remained significant with regard to knowledge about six modes of transmission (shaking hands, touching doorknobs, touching equipment, being in the same room, and touching toilet seats and bedsheets), eight means of preventing transmission (discarding needles, quarantine, and wearing gowns, masks, gloves, shoe protectors, double gloves, protective eyewear), and five attitudes (have knowledge to protect self, feel professionally competent, would not avoid caring for persons with AIDS, feel comfortable with the person's lover, and persons with AIDS can have nonsexual social contacts).

Although the followup results suggest that postprogram changes were largely retained, the followup respondents were self-selected volunteers who differed from the larger group in some important respects. The followup group had significantly fewer nurses and more "others"; 17 percent were males. Thirty percent had cared for someone with AIDS, which may partially explain both their interest in the followup and their level of knowledge. Also, historical events or media coverage during the intervening month could have affected responses.

\section{Conclusions}

The results suggest $(a)$ a need for education at all levels of the health care system, (b) the possibility of significant changes in knowledge and attitudes, and (c) the need to recognize that providers at different levels of responsibility come to educational programs with different knowledge and attitudes.

The care of persons with AIDS cannot be entrusted to people who believe that AIDS is transmitted by doorknobs, handshakes, or being in the same room. Provider beliefs are reminiscent of popular beliefs about syphilis earlier in the century. The "AIDS coffee cup" has its parallel in the "public drinking cup" once thought to transmit syphilis to innocent victims (17). As long as the beliefs of even a few providers remain at this level, it will be impossible to ensure a decent and humane level of care.

Although we were unable to observe changes in providers' behavior, the literature on continuing medical education suggests that changes in knowledge are related to behavior change (18-21).

Our study suggests that the greatest difference in knowledge and attitudes lies between those who. establish regulations for the care of persons with AIDS and those who provide inpatient care but have no supervisory responsibilities. In this study, education did not eliminate differences among the four groups. We suggest that there are needs for special educational programs directed at each group, taking into account preexisting differences in knowledge and attitudes $(22,23)$. With appropriate modifications, programs such as these can be used with school personnel, and with police, fire, corrections, and social welfare departments.

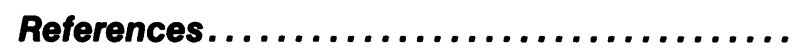

1. Curran, J. W., et al.: The epidemiology of AIDS: current status and future prospects. Science 229: 1352-1357, Sept. 27, 1985.

2. Curran, J. W.: The epidemiology and prevention of the acquired immunodeficiency syndrome. Ann Int Med 103: 657-662 (1985).

3. Gorman, M., Needle, R., Jones, J. T., and Kreuter, M. W.: AIDS health education risk-reduction strategies: implementation and evaluation efforts in 9 cities. Paper presented at the International Conference on Acquired Immunodeficiency Syndrome, Centers for Disease Control, Atlanta, GA, Apr. 14-17, 1985.

4. Massie, M. J., and Barbuto, J.: Medical staff responses to AIDS: management issues. Paper presented at the annual meeting of the American Psychiatric Association, Washington DC, May 10-16, 1986 (Abstract 65F).

5. Morin, S. F., and Batchelor, W. F.: Responding to the psychological crisis of AIDS. Public Health Rep 99: 4-9, January-February 1984.

6. Dilley, J. W.: Treatment interventions and approaches to care of patients with acquired immune deficiency syndrome. In Psychiatric implications of acquired immune deficiency syndrome, edited by S. E. Nichols and D. G. Ostrow. American Psychiatric Press, Washington, DC, 1984, pp. 65-92.

7. Kernoff, P. B.: AIDS, infectivity, and health care workers. Br J Haematol 60: 207-211 (1985).

8. Lusby, G. I.: AIDS: the impact on the health care worker. Front Radiat Ther Oncol 19: 164-167 (1985).

9. Nichols, S. E., and Ostrow, D. G., editors: Psychiatric implications of acquired immune deficiency syndrome. American Psychiatric Press, Washington, DC, 1984, pp. 62-80.

10. Holland, J. C., and Tross, S.: Psychosocial and neuropsychiatric sequelae of the acquired immunodeficiency syndrome and related disorders. Ann Intern Med 103: 760-764 (1985).

11. Nichols, S. E.: Psychosocial reactions of persons with the acquired immunodeficiency syndrome. Ann Intern Med 103: 765-767 (1985).

12. Cassens, B. J.: Social consequences of the acquired immunodeficiency syndrome. Ann Intern Med 103: 768-771 (1985).

13. Nichols, S. E.: The social climate when the acquired immune deficiency syndrome developed. In Psychiatric implications of acquired immune deficiency syndrome, edited by S. E. Nichols and D. G. Ostrow. American Psychiatric Press, Washington, DC, 1984, pp. 85-92. 
14. Centers for Disease Control: Recommendations for preventing transmission of human $\mathrm{T}$-Lymphotrophic virus, type III/lymphadenopathy associated virus in the workplace. MMWR 24: 45, Nov. 15, 1985.

15. Needlestick transmission of HTLV-III from a patient infected in Africa. Lancet No. 8416: 1376-1377, Dec. 15, 1984.

16. Centers for Disease Control: Update: evaluation of human T-lymphotrophic virus type III/lymphadenopathyassociated virus infection in health care personnel-United States. MMWR 34: 575-578, Sept. 27, 1985.

17. Brandt, A. M.: No magic bullet: a social history of venereal disease in the United States since 1880. Oxford University Press, New York, 1985.

18. Ferguson, K. J., Caplan, R. M., and Williamson, T. S.: Factors associated with behavior change in family physicians after CME presentation. J Med Educ 59: 662-666 (1984).
19. Cervero, R. M.: Continuing professional education and behavioral change: a model for research and evaluation. J Cont Ed Nurs 16: 185-188 (1985).

20. White, C. W., Abanese, M. A., Brown, D. D., and Caplan, R. M.: The effectiveness of continuing medical education in changing the behavior of physicians caring for patients with acute myocardial infarction: a controlled randomized trial. Ann Intern Med 102: 686-692 (1985).

21. Young, L. J., and Willie, R.: Effectiveness of continuing education for health professionals: a literature review. J Allied Health 13: 112-123 (1984).

22. Steinbrook, R., et al.: Ethical dilemmas in caring for patients with the acquired immunodeficiency syndrome. Ann Intern Med 103: 787-790 (1985).

23. Volberding, P. A.: The clinical spectrum of the acquired immunodeficiency syndrome: implications for comprehensive patient care. Ann Intern Med 103: 729-733 (1985).

\section{The Association of Smoking with Clinical Indicators of Altered Sex Steroids -a Study of 50,145 Women}

\author{
ARTHUR J. HARTZ, MD, PhD \\ SHERYL KELBER, MS \\ HAROLD BORKOWF, MD \\ ROBERT WILD, MD \\ BETH L. GILLIS, MD \\ ALFRED A. RIMM, PhD
}

Dr. Hartz and Dr. Wild are with the Milton S. Hershey Medical Center, Hershey, PA. Dr. Hartz is Director of Research in the Department of Family and Community Medicine, and Dr. Wild is Acting Chief of the Division of Reproductive Endocrinology.

The other authors are with the Medical College of Wisconsin. Ms. Kelber is Research Associate and Dr. Rimm is Chief, Division of Biostatistics and Clinical Epidemiology. Dr. Borkowf is Clinical Associate Professor in the Department of Gynecology, and Dr. Gillis is a resident in the Department of Family Practice.

Tearsheet requests to Alfred A. Rimm, PhD, Division of Biostatistics, Medical College of Wisconsin, P.O. Box 26508, Milwaukee, WI 53226.

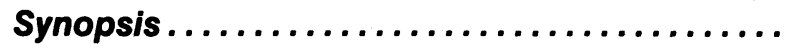

This study was designed to test the association of smoking with four clinically apparent conditions that may be related to altered sex steroids: natural and induced menopause, infertility, .oligomenorrhea, and hirsutism. Data were obtained from the personal inventories of 50,145 women ages 20-59 years in TOPS, a weight reduction program.

The age-adjusted odds ratios of each condition for heavy smokers compared with nonsmokers were 1.59 for natural menopause, 1.49 for induced menopause, 1.35 for infertility, 1.30 for oligomenorrhea among women younger than 40 years, 1.63 for oligomenorrhea among women 40-49 years, and 1.54 for hirsutism $(P<.05$ for oligomenorrhea and $P<.001$ for all other risks). The odds ratios were not substantially changed after adjustment for obesity, parity, and husband's education level. These results suggest that smoking may affect the ovaries or hormone metabolism, or both, with medical and cosmetic consequences.
$\mathrm{H}$ OW SMOKING RELATES to gynecologic abnormalities has been examined in several studies. It has been shown frequently that smoking is associated with natural menopause (1-6). Other studies have found smoking to be associated with the inability to become pregnant (6), lowered estrogen levels in the luteal phase (7), and alterations in the levels of gonadotropins and other hormones that may affect ovarian function (8).

One difficulty in evaluating the association of smoking with a given condition is that smokers may differ from nonsmokers in characteristics such as weight $(9,10)$ and socioeconomic status $(11)$. To isolate the association of smoking with a given 